Article

\title{
Spatial Distribution of Fragmentation by Diversion-Typed Hydroelectric Plant Exploitation in East Baoxing Catchment from 1999 to 2013
}

\section{Yong Huang ${ }^{1,2}$, Li Zheng ${ }^{3}$, Dongchuan Wang ${ }^{4, *}$, Wengang Chen ${ }^{4}$ and Qianqian Wang ${ }^{4}$}

1 Center for Ecological Research, Northeast Forest University, No. 26 Hexing RD., Xiangfan District, Harbin 150040, China; E-Mail: jiajia8211@126.com

2 Appraisal Center for Environment \& Engineering Ministry of Environmental Protection, No. 8 Beiyuan RD., Chaoyang District, Beijing 100012, China

3 Yunnan Academy of Scientific \&Technical Information, No. 246 Renmin Donglu, Kunming 650051, China; E-Mail: z179@live.cn

4 School of Geology and Geomatics, Tianjin Chengjian University, No. 26 Jinjing RD., Xiqing District, Tianjin 300384, China; E-Mails: mrwangdc@126.com (W.C.); wq1365216@163.com (Q.W.)

* Author to whom correspondence should be addressed; E-Mail: wangdongchuan@tcu.edu.cn; Tel.: +86-22-2377-3032.

\section{Academic Editor: Vincenzo Torretta}

Received: 1 December 2014 / Accepted: 18 March 2015 / Published: 24 March 2015

\begin{abstract}
In the Southwest Mountain areas, successive hydroelectric plant exploitation by humans on Baoxing River can exert a significant impact on regional landscape composition and structure. Taking East Baoxing River Catchment as the study area, the authors developed a method combining Moving Window based Calculation and Spatial Correlation Analysis to analyze the relationship between fragmentation and related spatial factors at a local scale, aiming to examine the spatial distribution rule of the landscape fragmentation and provide scientific support for the conservation of landscape ecology in the study area. From the perspective of the whole study area, although there is no clear relationship between the selected factors and the Change of DIVISION (CODIV), the comparison of $R$ values in the latter interval (2006-2013) with those in the former interval (1999-2006) proves that the human activities of plant building have led to the increase in the DIVISION value. At the local scale, results show that a high positive relationship exists between slope and CODIV $(R=0.857, p$-value $=0.05)$, while the relationship between river distance and CODIV is highly negative $(R=-0.837, p$-value $=0.01)$. A medium strong negative
\end{abstract}


relationship lies between elevation and CODIV, while there is almost no linear relationship between distance from Qiaoqi reservoir and CODIV.

Keywords: landscape fragmentation processes; moving window; change of division; hydroelectric cascade exploitation; zonal statistics

\section{Introduction}

Human activities can exert intense impacts on regional landscape composition and structure. Of all the novel kinds of disturbances that human beings have introduced in mountain rivers, Hydroelectric Cascade Exploitation (HCE), successive dam development on the same river [1], may be the most ubiquitous and significant of our activities. Tremendous economic benefits can be created from these dams, while, on the other hand, HCE disturbs fluvial process of the river, reduce river connectivity, fragment this watershed, and degrade adjacent land resources [2-5]. In many rivers of the world, eco-environmental degradations have taken place, leading to significant landscape fragmentation in the adjacent areas [6-11].

Landscape fragmentation is increasingly considered as an important environmental indicator in the fields of sustainable land use and biodiversity. In an ecological sense, fragmentation implies the division of natural ecosystems into smaller patches as the result of human activities, such as the transformation of forest and wetlands into agricultural or urban area [12]. Landscape fragmentation alters bio-geographical environments and reduces species habitats [13]. It plays a crucial role in the disaggregation of contiguous habitat into more dispersed and isolated patches, so that ecosystem functionality is impaired [14], which, in turn, may result in a decline in the individual populations, or even a regional extinction for entire populations across the landscape $[15,16]$. At the same time, it facilitates the spread of invasive species and reduces the ecosystem services that human society relies on. Therefore Landscape fragmentation is an essential subject in landscape ecology, conservation biology, and wildlife management [17]. It is important for hydropower project development and regional land use management to learn how hydropower development affects landscape structure.

Many studies have investigated the effects of HCE on the adjacent landscape structure. Bombino et al. [18] investigated the effects of check-dams on riparian vegetation in the Mediterranean environment. Gordon and Meentemeyer [19] examined the interacting effects of a dam on downstream changes in channel morphology and riparian vegetation in northern California and found that operation of the dam and land use patterns together influenced spatial and temporal changes in channel morphology and riparian vegetation. Ouyang et al. [1] employed landscape indices for fragmentation, shape and diversity to depict the characterization of the spatial-temporal landscape characteristics resulting from the accumulated impacts of HCE. Two different scales, watershed scale and on-site area, were used to compare the changes in grassland and water area [20] to show vegetation response to hydropower cascade exploitation in upper stream of Yellow River. The accumulated impact of cascade dams on stream flow, sand concentration and nutrient pollutant discharge were also analyzed [21], which 
were helpful for understanding the environmental features of the entire watershed. Most of the above researchers focused on the influencing degree evaluation of HCE on the landscape, however, few studies have attempted to identify the spatial-temporal distribution of landscape fragmentation [3,22]. Yang et al. [23] evaluated spatial characteristics of forest fragmentation in the Manwan Basin after dam construction using kernel density estimation (KDE). With GIS-based buffer analysis, Liu et al. [24] predicted and assessed the impacts of hydroelectric project construction on the ecological integrity of the Nuozhadu Nature Reserve. Therefore, more research methodologies are still needed to better explore this problem.

Owing to its terrain advantage, Baoxing River Catchment is listed as one of the key development bases of medium-sized hydropower in Sichuan province. Two nature reserves, Fengtongzhai National nature reserve (mainly giant panda) and Baoxing Rare Fish nature reserve lie in this research area. Power plant construction leads to land use/cover change and landscape fragmentation, and inevitably impacts on the surrounding environment. Taking East Baoxing River Catchment as the study area, using a method combining Moving Window based Calculation and Spatial Correlation Analysis, this paper aims to show the spatial distribution rule of landscape fragmentation processes, and the impact, which related spatial factors have on the fragmentation process. With this study, we aim to provide scientific support for reducing the impacts of fragmentation on species habitats, ecosystem functionality and ecosystem services.

\section{Materials and Methods}

\subsection{Study Area}

The study area is East Baoxing River catchment (Yaan, Sichuan Provence, China), located at $30^{\circ} 27^{\prime} \mathrm{N}-30^{\circ} 57^{\prime} \mathrm{N}$ and $102^{\circ} 28^{\prime} \mathrm{E}-103^{\circ} 02^{\prime} \mathrm{E}$ in the Northeast of Baoxing River catchment, with a drainage area of $1396 \mathrm{~km}^{2}$ (Figure 1). It runs about $83 \mathrm{~km}$ long with a large slope gradient of 38.6\%. Climate in the study area belongs to the subtropical monsoon climate zone, but it changes significantly with the vertical change of mountain altitude $[10,11]$. Mountainous terrain dominates this catchment, and the terrain gradually reduced from northwest to southeast. On the North and west boundary lie Jiajin Mountain and Dadu River, with the highest altitude up to $5000 \mathrm{~m}$, and on the east boundary are Min River and Qionglai Mountain, with the altitude of 2000-4000 m.

The East River Catchment is mainly covered with dense forests and grassland, in addition to a small amount of arable land, houses, roads and water, with vegetation coverage of over $90 \%$. Exposed rock in the basin is relatively fragmented and weathering, coupled with high mountains and steep slopes, geological disasters like landslides, collapse or mudslides occurs in case of heavy rain and flash floods.

From the end of last century, the "One-reservoir and Eight-cascade" hydropower station project has been carried out on Baoxing River. Three of those stations are located on East Baoxing River, including Qiaoqi, Minzhi, and Baoxing station. 


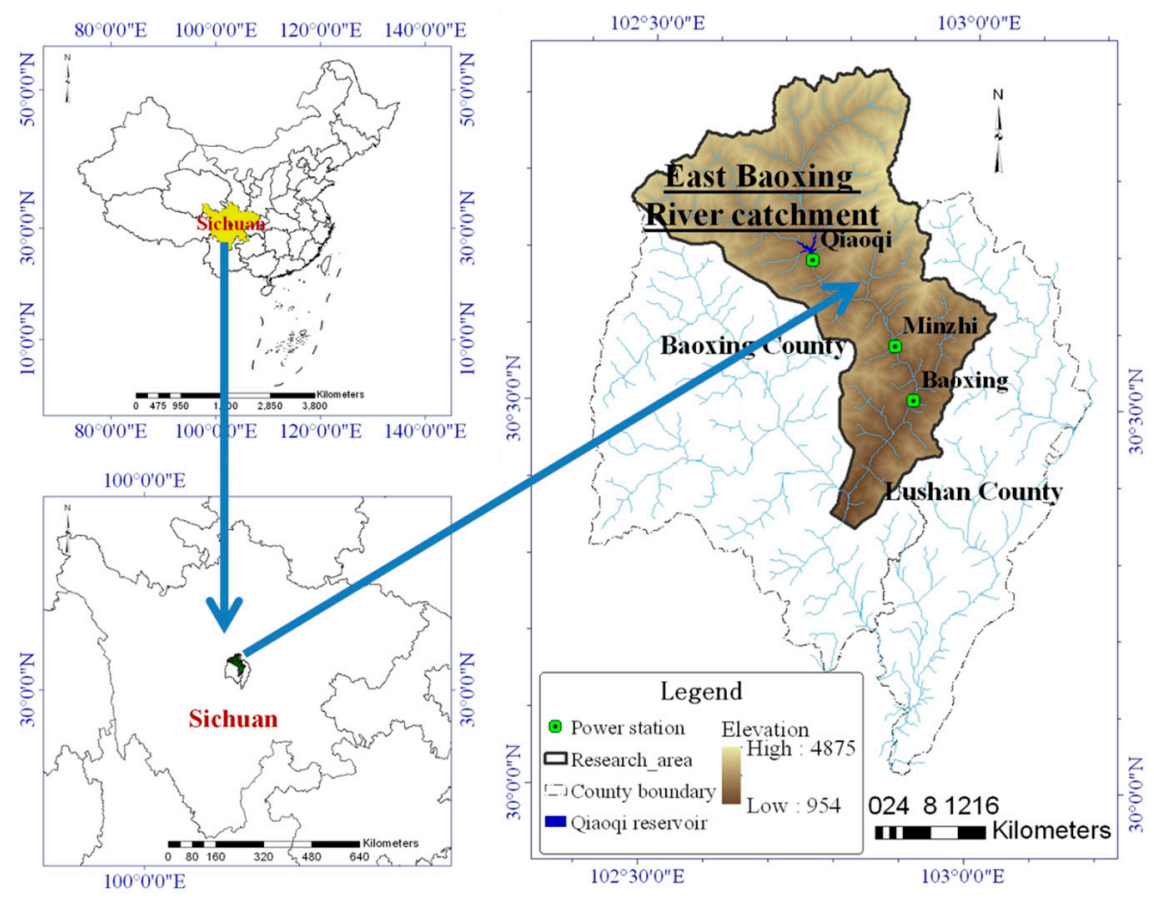

Figure 1. Location of the study area.

\subsection{Data Preprocessing and Interpretation}

Landsat Remote Sensing images were collected (The data set is provided by Geospatial Data Cloud, Computer Network Information Center, Chinese Academy of Sciences. http://www.gscloud.cn), including Landsat5 TM (13 June 2001,with cell size $30 \mathrm{~m}$ ) and Landsat7 ETM+ (19 December 1999; 2 May 2006; 21 May 2013, with cell size 15 m).

Image fusions were carried out between the band 8 of Landsat7 ETM+ (19 December 1999) and Landsat5 TM (13 June 2001) to enhance the resolution up to $15 \mathrm{~m}$, and at the same time, keeping the spectral characteristics of Landsat5 TM. Landsat data of the two time nodes were unified to the same spatial resolution $(15 \mathrm{~m})$ and the same phase (May or June) to make the change detection more accurate and reasonable.

High resolution imagery like Quickbird (from Google Earth) and CBERS2B HR image (Data provided: China Resources Satellite Application Center; Data Source: China-Brazil Earth Resources Satellite), together with field sample points, were referenced to ensure higher accuracy (higher than $90 \%$ for each time node) of the interpretation of land use/cover type. In addition, Digital Elevation Data (ASTER GDEM $30 \mathrm{~m}$ ) of East Baoxing catchment were used to delineate river net, slope and aspect.

Image atmospheric and geometric corrections were carried out to ensure that the geometric errors between time nodes were kept within one pixel. Images first were classified into small subclasses, which in the end were combined into big classes, including forest, grassland, wetland, farmland, constructive land, and bare land.

Combined with artificial vectorization method, object-oriented supervised classification method was used in ENVI 5.0 to extract land use/cover types. After being segmented, polygon objects created from homogeneous pixels would become the minimum computable spatial unit of the imagery. The sizes of the considered objects would reach a maximum size according to the segmentation threshold, 
which, therefore, greatly influences the result of the landscape Division Index. However, the research objective of this paper is to investigate the process of fragmentation. To keep the same segmentation threshold for all the three time nodes therefore is crucial. Trial and error method was used to optimize the segmentation threshold. After the comparison between numerous settings, the same parameters were finally set for the three time nodes at 50.0 for the Segment Scale Level and 90.4 for the Merge Level. Images were interpreted into land use/cover thematic maps, which show the distribution of land use/cover types in 1999, 2006 and 2013 in East Baoxing River Catchment respectively.

200 ground truthing points were acquired for the accuracy assessment. The overall accuracy of single-date image classifications is more than $90 \%$ for all the three time nodes, with Kappa coefficients ranging from 0.82 to 0.87 . The classification yields a satisfactory result, meeting with the research aims of this paper.

\subsection{Landscape Division Index}

The degree of landscape fragmentation is often shown as the increase of patch number, the decrease of mean patch size or the increase of total edge amount. Different indexes are provided in Fragstats 4.1 software, in which Division Index is based on the cumulative patch area distribution and is interpreted as the probability that two randomly chosen pixels in the landscape are not situated in the same patch, for which it can be more adaptively used to compare the degree of fragmentation between different time nodes. The index can be acquired using the formula as below [25].

$$
\text { Division }=\left[1-\sum_{\mathrm{i}=1}^{\mathrm{m}} \sum_{\mathrm{j}=1}^{\mathrm{n}}\left(\frac{\mathrm{a}_{\mathrm{ij}}}{\mathrm{A}}\right)^{2}\right]
$$

Division, here, is Landscape Division Index, in percent $(0 \leq$ Division $<1)$; $a_{\mathrm{ij}}$ is the area of patch ij $\left(\mathrm{m}^{2}\right)$; A is the total landscape area $\left(\mathrm{m}^{2}\right)$.

Division is 0 when the landscape consists of only one single patch. The higher the value of Division is, the more fragment the landscape is. DIVISION approaches 1 when the focal patch type consists of many single small patches with the size of one raster cell.

\subsection{Grid of Division Index Produced by Moving Window}

Landscape metrics are generally computed for the entire extent of the landscape and quantify the structure of the entire mosaic over the full extent of the data, which is called global landscape structure. In this case, only one value is obtained in the computation of this kind of index, through which it is difficult to show the spatial distribution of the structure characteristics this index transmits.

In this paper, the Division Index was computed at a local scale to get a new grid of Division for each time node respectively. Local values were calculated via a moving square window placed over each cell one at a time, where the value in each window is returned to the focal cell. The metric is literally the same as the one for the global landscape. The only difference is that it is applied to the local window around each focal cell [24]. Thus, a new grid, in which the cell value represents the local neighborhood structure, is produced and can be easily used to overlay with other grid layers to show spatial distribution of the structure characteristics. Trial and error method was also used to set the side 
length of the moving window. It was found that the larger the side length is, the more difficult it was for the software to run. And $0.5 \mathrm{~km}, 1 \mathrm{~km}, 2 \mathrm{~km}, 3 \mathrm{~km}$ and $5 \mathrm{~km}$ were tried as the side length. It was showed that the $1 \mathrm{~km}$ side length could record the fragmentation process more clear and exert more reasonable results.

\subsection{Spatial Characteristics Analysis of Division Change through Spatial Influence Factors}

\subsubsection{Acquisition of Change Layer of Division}

Change Layers of Division (grid layer) were computed through raster calculation in ARCGIS 10.2 by subtraction, which would be used in the later analysis of this paper.

Values of the calculated grid layers indicate the change of the index of Division in the respective time interval. Positive values imply an increase and negative values a decrease in fragmentation. The higher the value is, the more fragmented this area turns. Therefore, study on the spatial distribution characteristics of Change of Division (CODIV) can perfectly show spatial change of fragmentation in this landscape area.

\subsubsection{Selection of Spatial Influence Factors}

Many factors may contribute to the fragmentation of landscape, and among these factors, the ones with the greatest impact are related to human activities. The influence of human activities furthermore tends to depend on other spatial factors like the distance to residential area, the distance to roads, and so on. In this paper, the following factors were selected to be overlaid with the layer of CODIV to make the spatial analysis.

(1) Distance from river line (DFR)

In the study area, most residents live close to the river bank and roads extend along the river line too. Therefore, river was extracted from Digital Elevation Data and distance from it was calculated for each grid in the study area. Distance to roads were not selected, for roads extend along rivers, the distance to rivers is an alternative to the distance to roads.

(2) Distance from Qiaoqi Reservoir (DFQ)

Located in the study area, Qiaoqi Reservoir is the only reservoir of the "One-reservoir and Eight-cascade" hydropower station project, which has exerted great impacts on the fragmentation of the local landscape. Therefore, distance from Qiaoqi Reservoir was also selected.

(3) Elevation (ELV) and (4) Slope (SLP)

Terrain factors are among the main factors influencing human activities in mountainous area, which may further exert influence on the process of landscape fragmentation. Therefore, elevation and slope were selected as important variables for human impact.

The selected spatial influence factors were computed in ARCGIS. Layers of DFR and DFQ were generated by Euclidean Distance tool from main rivers and Qiaoqi reservoir separately. The slope layer was identified from the DEM (Digital Elevation Data) raster surface. How these influence distributed would be analyzed through spatial correlation analysis. These reclassified grid layers were also utilized to calculate area statistics in the following analysis. 


\subsubsection{Spatial Correlation Analysis}

Relationships between fragmentation and spatial influence factors were made clear by calculating the correlation coefficients between the corresponding grid layers, as a measure of dependency between these layers. Band Collection Statistics in ARCGIS tools were used to provide statistics for the correlation analysis of a set of raster bands using the Compute Covariance and Correlation Matrices option.

\subsubsection{Zonal Statistics by Reclassification Zones of Different Factors}

In order to make the relationships more clear, reclassifications were carried out on each layer of the selected influence factors. Different classes in each reclassified layer were taken as zones in the zonal statistics and the mean of the Division values in each certain zone were figured out. The correlation between the change of CODIV was calculated based on the class values of each influence factor.

Class upper boundary and area were all listed in the following tables separately (Table 1).

Table 1. Reclassification zones of different factors.

\begin{tabular}{ccccccccc}
\hline & \multicolumn{2}{c}{ Slope } & \multicolumn{2}{c}{ Elevation } & \multicolumn{2}{c}{ River Distance } & \multicolumn{2}{c}{ Qiaoqi Distance } \\
\cline { 2 - 9 } Class & $\begin{array}{c}\text { Upper } \\
\text { Boundary } \\
\text { (Degree) }\end{array}$ & $\begin{array}{c}\text { AREA } \\
\left.\mathbf{( h m}^{2}\right)\end{array}$ & $\begin{array}{c}\text { Upper } \\
\text { Boundary } \\
\text { (Degree) }\end{array}$ & $\begin{array}{c}\text { AREA } \\
\left.\mathbf{( h m}^{\mathbf{2}}\right)\end{array}$ & $\begin{array}{c}\text { Upper } \\
\text { Boundary } \\
\text { (Degree) }\end{array}$ & $\begin{array}{c}\text { AREA } \\
\left.\mathbf{( h m}^{2}\right)\end{array}$ & $\begin{array}{c}\text { Upper } \\
\text { Boundary } \\
\text { (Degree) }\end{array}$ & $\begin{array}{c}\text { AREA } \\
\left.\mathbf{( h m}^{2}\right)\end{array}$ \\
\hline 1 & 8 & 2402.01 & 2000 & $13,953.87$ & 500 & $11,182.68$ & 500 & 1126.53 \\
2 & 15 & 8676.81 & 2500 & $20,727.99$ & 1000 & 9869.13 & 1000 & 921.15 \\
3 & 25 & $31,358.43$ & 3000 & $28,274.13$ & 2000 & $17,962.11$ & 2000 & 2177.73 \\
4 & 35 & $48,940.02$ & 3500 & $29,028.33$ & 3000 & $15,786.09$ & 3000 & 2746.26 \\
5 & 45 & $30,071.88$ & 4000 & $26,150.22$ & 5000 & $24,680.61$ & 5000 & 7335.81 \\
6 & 55 & 6140.97 & 4500 & 9769.86 & 8000 & $22,700.34$ & 8000 & $13,702.68$ \\
7 & 75 & 597.24 & 5000 & 452.43 & 12,000 & $19,006.65$ & 12,000 & $21,871.71$ \\
8 & & & & & 18,000 & 6962.31 & 18,000 & $33,168.42$ \\
9 & & & & & 25,000 & 17.64 & 25,000 & $45,117.27$ \\
\hline
\end{tabular}

Taking every class of each influence factor as the zonal area, MEAN statistics of CODIV were carried out on the layer of CODIV from 1999 to 2013. Liner correlation analyses were carried out between Upper boundary and MEAN of CODIV for each influence factors.

\section{Results and Discussion}

\subsection{Change Analysis on the Division Index}

Division indices were first computed at the entire landscape scale. Results show that Division rises with time, from 0.5212 in 1999 to 0.5248 in 2006 and at last up to 0.5305 in 2013. In the past decade, many power stations were built up on East Baoxing River, esp. those water diversion-typed small power stations, which cut off the natural river line, and artificial channels were dredged to diverse water to power stations. This way, landscape fragmentation increased during the analyzed time interval in the area. This is consistent with the intensity of human activities in the hydropower development. 
Division index at local scale was computed through a square moving window with a size of $1 \mathrm{~km}^{2}$ for each time node respectively. In order to make it clear how the fragmentation took place in the whole study area, grid layers of CODIV for the former interval (from 1999 to 2006), the latter interval (from 2006 to 2013) and the whole interval (from 1999 to 2013) were separately acquired by subtraction of Division layers of the corresponding time nodes (Figure 2). Positive values imply an increase in fragmentation degree, and negative values vice versa decrease. Quantile breaks were used to classify the values to make the figure more readable. Here gray color indicates no change $(-0.0023-0.0077)$, green color indicates a drop of DIVISION, and red color, a rise of DIVISION.

Statistics of Figure 2 showed that during the whole time range from 1999 to 2013, the degree of fragmentation had been worsening from the view of the whole catchment. And more serious fragmentation took place in the latter interval from 2006 to 2013 than the former from 1999 to 2006. The trend of China's hydropower development in southwest mountain stream with high intensity may have impacted and would exert great impact on the local landscape ecology if it continues at an unchanged pace.

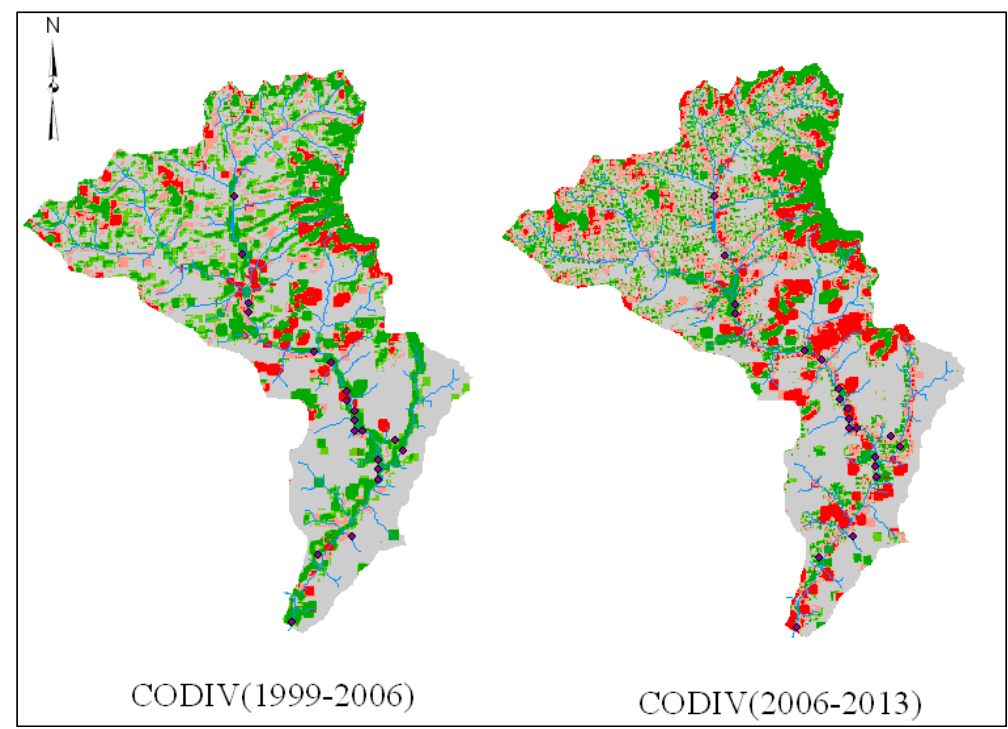

(a)

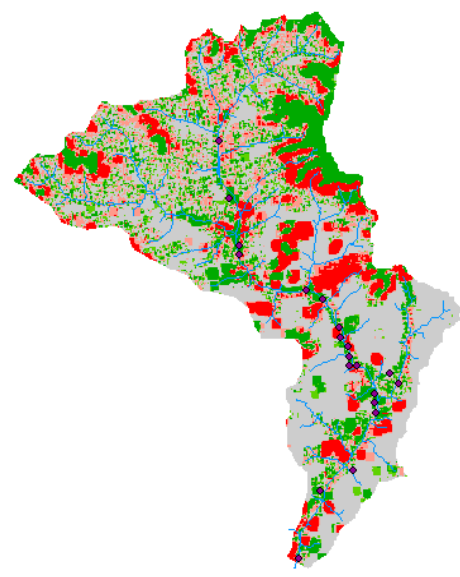

$\operatorname{CODIV}(1999-2013)$

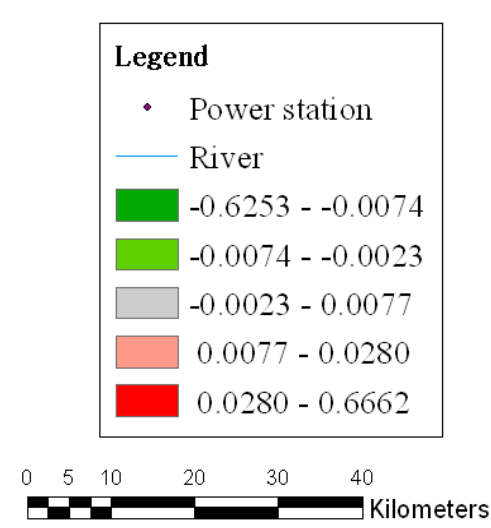

(b)

Figure 2. Grid layers of CODIV generated by layer subtraction. (a) CODIV of the two sections; (b) CODIV of the whole period. 


\subsection{Spatial Correlation Analysis Based on the Whole Range of Study Area}

Layers of DFR, DFQ, SLP and ELV were applied to make spatial spearman correlation analysis with layers of CODIV in the three intervals generated before. Correlation coefficients (R) were listed in Table 2. All $p$-values in the correlation analysis here were below 0.05 (significant at the 0.05 level).

Table 2. Correlation coefficients (r) between different layers.

\begin{tabular}{cccc}
\hline & CODIV1999 2006 & CODIV2006 2013 & CODIV1999 2013 \\
\hline DFR & -0.0115 & -0.1483 & -0.1356 \\
DFQ & -0.0219 & 0.0379 & 0.0159 \\
ELV & -0.0286 & -0.1713 & -0.1662 \\
SLP & 0.0062 & 0.0861 & 0.0797 \\
\hline
\end{tabular}

It can be inferred that all the correlation coefficients (R) were close to zero (Table 2), which indicates that, just judging from the liner relationship between cell values in the raster layers, no obvious relationships exists between these factors and the CODIV from the view of the whole range of study area. While to compare $r$ values of the latter interval (CODIV2006 2013) with those of the former (CODIV1999 2006), the absolute value had all clearly increased, esp. for DFR and ELV (in negative direction), showing that there existed a rise in the correlation for the spatial influence factors with CODIV, though in the former interval $R$ values were close to zero. Most of the power plants were being built or began to be built in the latter interval, especially the first three biggest power stations in East Baoxing River Catchment (i.e., Qiaoqi Power Station, Baoxing Power Station and Minzhi Power Station). Human activities began to exert more effects on the study area. With the increase of elevation or the distance form river line, change of DIVISION took a slight tendency of decrease, which in accord with the fact that the human activities of plant building were all close to rivers with relatively lower elevation, leading to the increase in the DIVISION value (high CODIV value).

\subsection{Correlation Analysis by Zonal Statistics}

After layer reclassification of each influence factor, Spearman correlation analyses were carried out between the Upper boundary and MEAN of CODIV for each influence factors (Table 3).

Table 3. Results of correlation analyses between the Upper boundary of each influence factors and MEAN of CODIV.

\begin{tabular}{ccccc}
\hline & SLP & ELV & DFR & DFQ \\
\hline$R$ & 0.857 & -0.770 & -0.837 & 0.241 \\
$p$-value & 0.05 & 0.05 & 0.01 & 0.533 \\
\hline
\end{tabular}

Results show that high negative relationship exists between DFR and CODIV, where $\mathrm{R}$ is -0.837 (Table 3). The "One-reservoir and Eight-cascade" hydropower station project have been carried out on Baoxing River From the end of last century. On East Baoxing River are located Qiaoqi, Minzhi, and Baoxing station. Qiaoqi Reservoir is just the origin reservoir of this "One-reservoir and Eight-cascade" project. Except for these stations, according to our recent survey, till December 2013, there were 18 power plants being under construction or having been built in East Baoxing River Catchment, and 
most of them were privately constructed. All of these plants were water diversion-typed small power stations. Diversion channels were constructed along river line, so almost no natural river exists except for several source tributaries. Most of these projects were being built or completed in the later interval from 2006 to 2013. These disturbances on the river had led to great effects on the adjacent landscape, which had resulted in the aggravation of landscape fragmentation in East Baoxing catchment. The closer it is to the river line, the greater the effects emerge, and that is to say, high negative relationship exists between the distance from river line and the change of DIVISION.

As for the DFQ, different from DFR, there is no obvious relationship with CODIV (Table 3). Although the construction of the reservoir took great effect on the landscape around, the surface of the reservoir covers a large number of different former small patches, which lowers the value of DIVISION index. While owing to human activities, the value of DIVISION may be higher near to the bank of the reservoir. Therefore, there is no clear linear relationship between DFQ and CODIV. What is more, Qiaoqi power plant is also a diversion-typed power station, and the tunnel engineering and the diversion project both take on a linear shape running along the river bank, which perfectly explains why there is high negative relationship between DFR and CODIV, while no relationship exists between DFQ and CODIV.

A high drop of elevation in the river line played an important role in the construction of the power station. Nevertheless, construction activities often took place along the drop line of the elevation, so only a medium negative relationship lies between ELV and CODIV (Table 3). Most of the time, the effects of human activities (esp. engineering constructions and agricultural activities) on landscape patterns have been less ubiquitous and less straightforward in high-elevation landscapes than in low-elevation landscapes [26], so fragmentation may be usually much more serious with the dropping of elevation. While the land with higher elevation often covered with forests (e.g., Fengtongzhai National nature reserve), which usually remain unchanged owing to the policy of forest conservation in the mountainous area. Therefore, negative relationship exists between elevation and the change of DIVISION.

While compared to the elevation, a high positive relationship exists between SLP and CODIV, where $R$ is 0.857 (Table 3). Most often, high slope leads to high DIVISION, and under the disturbance of human activities of power station construction, it is more easily further fragmented. What is more, according to the relief of the study area, steep hillside lie along both sides of the river line, so more frequent interferences emerge on that high slope hillside, which explains the high positive relationship with CODIV.

The authors applied a method combining Moving Window based Calculation and Spatial Correlation Analysis to analyze the relationship between fragmentation and related spatial factors at a local scale. In this way, this research can provide scientific support for the conservation of landscape ecology in the study area by reducing the impacts fragmentation has on the species habitat, ecosystem functionality and ecosystem services. Different upper boundaries in the reclassification of influence factors may also produce some effects on the analysis result. While considering that these effects would exert equally on the former and latter period, the results of CODIV should not be impacted. When calculating metrics with moving window, side length of the window can exert great effects on the results. In this paper, trial and error method was used to set the side length of the moving window. Although $1 \mathrm{~km}$ was selected as the most suitable one, it is only a result of subjective judgment to some 
extent. Further research would be carried out to find a better way to decide the side length in our future research.

\section{Conclusions}

The impacts of power plant construction on the landscape have been widely researched, but the spatial distribution of the impacts on the landscape fragmentation over construction phase is still little studied. Based on Landsat Remote Sensing images, grid layers of the division index were computed through a square moving window, so that a change of division can be used to make spatial correlation analysis with the selected spatial influence factors. Changes of CODIV with the change of reclassification value of each layer of influence factors were analyzed by zonal statistics. Results show that:

(1) Moving window based fragmentation index calculation combined with Spatial Correlation Analysis can clearly show the spatial distribution rule of the landscape fragmentation and its relationship with related spatial factors on a local scale.

(2) Although there is almost no relationship between the selected factors and CODIV from the view of the whole range of study area, when comparing the latter with the former intervals, it proved that the human activities of plant building led to the increase in the DIVISION value.

(3) Correlation analysis after reclassification of the selected factors shows that high positive relationship exists between SLP and CODIV, where $r$ is 0.857 , while the relationship between DFR and CODIV is high negative correlation, where $r$ is -0.837 . Medium negative relationship lies between ELV and CODIV, while there is no obvious linear relationship between DFQ and CODIV.

In conclusion, human activities of plant construction engender greater impact on the fragmentation in East Baoxing catchment. And the fragmentation process is highly related to the distance from river line and slope. Results for the analysis of spatial distribution rule of fragmentation can facilitate decision-makers in ecological conservation and restoration, and more attention should be paid on the locations where it is close from river line with steep hillside, which is of great importance for regional environmental management.

\section{Acknowledgments}

This research is supported by Environmental Impact Post-evaluation project of hydrological power exploitation in Baoxing River. The authors would like to thank the whole staff of the project. It is also supported by Tianjin Science and Technology Development Foundation of Higher Education (20120526). And we are also grateful to China Resources Satellite Application Center and to Geospatial Data Cloud, Computer Network Information Center, Chinese Academy of Sciences for providing RS imagery data.

\section{Author Contributions}

Yong Huang and Dongchuan Wang conceived and designed the research; Yong Huang generally supervised the research group. Dongchuan Wang drafted the article. Li Zheng and Wengang Chen collected and processed the data; Dongchuan Wang, Wengang Chen, Qianqian Wang and Li Zheng 
interpreted and analyzed the data. All authors have revised the article critically and approved the final manuscript.

\section{Conflicts of Interest}

The authors declare no conflict of interest.

\section{References}

1. Ouyang, W.; Skidmore, A.K.; Hao, F.H.; Toxopeus, A.G.; Abkar, A. Accumulated effects on landscape pattern by hydroelectric cascade exploitation in the Yellow River basin from 1977 to 2006. Landsc. Urban Plan. 2009, 93, 163-171.

2. Lü, Y.H.; Sun, R.H.; Fu, B.J.; Wang, Y.F. Carbon retention by check dams: Regional scale estimation. Ecol. Eng. 2012, 44, 139-146.

3. Zhao, Q.H.; Liu, S.L.; Deng, L.; Dong, S.K.; Yang, Z.F.; Liu, Q. Determining the influencing distance of dam construction and reservoir impoundment on land use: A case study of Manwan Dam, Lancang River. Ecol. Eng. 2013, 53, 235-242.

4. Miao, C.Y.; Ni, J.R.; Borthwick, A.G.L. Recent changes of water discharge and sediment load in the Yellow River basin, China. Progress Phys. Geogr. 2010, 34, 541-561.

5. Miao, C.Y.; Ni, J.R.; Borthwick, A.G.L.; Yang, L. A preliminary estimate of human and natural contributions to the changes in water discharge and sediment load in the Yellow River. Glob. Planet. Chang. 2011, 76, 196-205.

6. Wang, Z.Y.; Wu, B.S.; Wang, G.Q. Fluvial processes and morphological response in the Yellow and Weihe Rivers to closure and operation of Sanmenxia Dam. Geomorphology 2007, 91, 65-79.

7. Zhang, S.R.; Lu, X.X.; Higgitt, D.L.; Chen, C.T.A.; Han, J.T.; Sun, H.G. Recent changes of water discharge and sediment load in the Zhujiang (Pearl River) Basin, China. Glob. Planet. Chang. 2008, 60, 365-380.

8. Miao, C.Y.; Duan, Q.Y.; Sun, Q.H.; Li, J.D. Evaluation and application of Bayesian multi-model estimation in temperature simulations. Progress Phys. Geogr. 2013, 37, 727-744.

9. Miao, C.Y.; Duan, Q.Y.; Sun, Q.H.; Huang, Y.; Kong, D.X.; Yang, T.T.; Ye, A.Z.; Di, Z.H.; Gong, W. Assessment of CMIP5 climate models and projected temperature changes over Northern Eurasia. Environ. Res. Lett. 2014, doi:10.1088/1748-9326/9/5/055007.

10. Sun, Q.H.; Miao, C.Y.; Duan, Q.Y. Projected changes in temperature and precipitation in ten river basins over China in 21st century. Int. J. Climatol. 2014, doi:10.1002/joc.4043.

11. Sun, Q.H.; Miao, C.Y.; Duan, Q.Y.; Kong, D.X.; Ye, A.Z.; Di, Z.H.; Gong, W. Would the "real" observed dataset stand up? A critical examination of eight observed gridded climate datasets for China. Environ. Res. Lett. 2014, doi:10.1088/1748-9326/9/1/015001.

12. Rutledge, D. Landscape Indices As Measures of the Effects of Fragmentation: Can Pattern Reflect Process? (DOC Science Internal Series 98); Department of Conservation: Wellington, New Zealand, 2003; pp. 7-9.

13. Jaeger, J.A.G.; Raumer, H.G.S.V.; Esswein, H.; Müller, M.; Schmidt-Lüttmann, M. Time series of landscape fragmentation caused by transportation infrastructure and urban development: A case study from Baden-Württemberg, Germany. Ecol. Soc. 2007, 12, 1-28. 
14. Saunders, D.A.; Hobbs, R.J.; Margules, C.R. Biological consequences of ecosystem fragmentation: A review. Conserv. Biol. 1991, 5, 18-32.

15. With, K.A.; King, A.W. Dispersal success on fractal landscapes: A consequence of lacunarity thresholds. Landsc. Ecol. 1999, 14, 73-82.

16. With, K.A.; King, A.W. Extinction thresholds for species in fractal landscapes. Conserv. Biol. 1999, 13, 314-326.

17. Collinge, S.K. Ecology of Fragmented Landscapes, 1st ed; The Johns Hopkins University Press: Baltimore, MD, USA, 2009; pp. 3-5.

18. Bombino, G.; Tamburino, V.; Zimbone, S.M. Assessment of the effects of check-dams on riparian vegetation in the mediterranean environment: A methodological approach and example application. Ecol. Eng. 2006, 27, 134-144.

19. Gordon, E.; Meentemeyer, R.K. Effects of dam operation and land use on stream channel morphology and riparian vegetation. Geomorphology 2006, 82, 412-429.

20. Ouyang, W.; Hao, F.H.; Zhao, C.; Lin, C. Vegetation response to 30 years hydropower cascade exploitation in upper stream of Yellow River. Commun. Nonlinear Sci. Numer. Simul. 2010, 15, 1928-1941.

21. Ouyang, W.; Hao, F.H.; Song, K.Y.; Zhang, X.A. Cascade Dam-Induced Hydrological Disturbance and Environmental Impact in the Upper Stream of the Yellow River. Water Resour. Manag. 2011, 25, 913-927.

22. Zhao, Q.H.; Liu, S.L.; Deng, L.; Dong, S.K.; Cong, C.; Wang, W.; Wang, C.; Yang, Z.F.; Yang, J.J. Landscape change and hydrologic alteration associated with dam construction. Int. J. Appl. Earth Observ. Geoinf. 2012, 16, 17-26.

23. Yang, J.J.; Liu, S.L.; Wang, C.; Deng, L.; Dong, S.K. Forest pattern dynamics and landscape connectivity changes in the Manwan Basin after dam construction in the Lancang River, China. Landsc. Ecol. Eng. 2014, 10, 77-83.

24. Liu, S.L.; Zhao, Q.H.; Wen, M.X. Assessing the impact of hydroelectric project construction on the ecological integrity of the Nuozhadu Nature Reserve, southwest China. Stoch. Environ. Res. Risk Assess. 2013, 27, 1709-1718.

25. McGarigal, K.; Cushman, S.A.; Neel, M.C.; Ene, E. FRAGSTATS: Spatial Pattern Analysis Program for Categorical Maps. Available online: http://www.umass.edu/landeco/research/ fragstats/fragstats.html (accessed on 20 June 2005).

26. McGarigal, K.; Romme, W.H.; Crist, M.; Roworth, E. Cumulative effects of roads and logging on landscape structure in the San Juan Mountains, Colorado (USA). Landsc. Ecol. 2001, 16, 327-349.

(C) 2015 by the authors; licensee MDPI, Basel, Switzerland. This article is an open access article distributed under the terms and conditions of the Creative Commons Attribution license (http://creativecommons.org/licenses/by/4.0/). 